Situs Jurnal : $\underline{\text { http://ejurnal.stiepancasetia.ac.id/index.php/jieb }}$

Jilid 4 Nomor 3 November 2018

Hal $411-418$

\title{
PENGARUH MOTIVASI KERJA DALAM MENINGKATKAN PRODUKTIVITAS KERJA KARYAWAN PADA PT. SARIGUNA PRIMA TIRTA PULAU SARI KECAMATAN BATI-BATI
}

\section{Syarkani*}

Abstract: Employee work motivation in an organization can be considered simple and can also be a complex problem, because basically humans are easy to be motivated by giving what they want. The purpose of this study was to determine and prove the effect of work motivation on employee work productivity at PT. Sariguna Prima Tirta Pulau Sari Bati-Bati District, Tanah Laut Regency. The main data was obtained through questionnaires to respondents as many as 44 people who were determined by purposive sampling, then supported by the results of observations and direct interviews with respondents. Data analysis was carried out with the help of the SPSS program. It was concluded that the results of the Simple Regression Equation in this study were $\mathrm{Y}=18.165+0.719 \mathrm{X}$. Based on the results of the $t$ test, it was found that the work motivation variable had a positive and significant effect on work productivity, because at the $5 \%$ significance level $\mathrm{t}$ counted greater than table $(8.510>2,02)$. The coefficient of determination (r2) is 0.633 which means the ability of the work motivation variable $(\mathrm{X})$ can explain the variable work productivity $(\mathrm{Y})$ of $63.3 \%$ while the remaining $36.7 \%$ is influenced by other variables not examined in this study.

\section{Keywords: motivation, productivity, Bati-Bati Subdistrict}

Abstrak: Motivasi kerja karyawan dalam suatu organisasi dapat dianggap sederhana dan dapat pula menjadi masalah yang komplek, karena pada dasarnya manusia mudah untuk dimotivasi dengan memberikan apa yang menjadi keinginannya. Tujuan penelitian ini adalah untuk mengetahui dan membuktikan pengaruh motivasi kerja terhadap produktivitas kerja karyawan pada PT. Sariguna Prima Tirta Pulau Sari Kecamatan Bati-Bati Kabupaten Tanah Laut. Data utama diperoleh melalui penyebaran angket kepada responden sebanyak 44 orang yang ditetapkan secara purposive sampling, kemudian didukung dengan hasil observasi dan wawancara langsung dengan responden. Analisis data dilakukan dengan bantuan program SPSS. Disimpulkan bahwa hasil Persamaan Regresi Sederhana dalam penelitian ini adalah Y $=18,165+0,719 \mathrm{X}$. Berdasarkan hasil uji t diketahui variabel motivasi kerja berpengaruh positif dan signifikan terhadap poduktivitas kerja, karena pada taraf signifikasi $5 \% \mathrm{t}$ hitung lebih besar dari t tabel $(8,510>2,02)$. Koefisien determinasi $(\mathrm{r} 2)$ sebesar 0,633 yang berarti kemampuan variabel motivasi kerja (X) dapat menjelaskan variabel produktivitas kerja (Y) sebesar $63,3 \%$ sedangkan sisanya $36,7 \%$ dipengaruhi oleh variabel lain yang tidak diteliti dalam penelitian ini.

Kata kunci : motivasi, produktivitas, Kecamatan Bati-Bati

\section{Latar Belakang}

PT Sariguna Prima Tirta adalah salah satu perusahaan yang bergerak dalam pembuatan minuman dengan merk Anda, dalam menjalankan usahanya perusahaan ini didukung oleh 
sumber daya manusia yang cukup banyak yang terbagi menjadi dalam tiga shif atau tiga kelompok kerja. Jam kerja PT. Sariguna Prima Tirta Pulau Sari Kecamatan Bati-Bati Kabupaten Tanah Laut yang terbagi dalam tiga shif yaitu pagi, sore dan malam. Shif pagi dimulai pada pukul 08.00 Wita istirahat pukul 12.00 Wita dan berakhir pada pukul 16.00 Wita. Shif sore dimulai pada pukul 16.00 Wita istirahat pukul 19.00 Wita dan berakhir pada pukul 24.00 Wita.Shif malam dimulai pada pukul 24.00 Wita istirahat pukul 04.00 Wita dan berakhir pada pukul 08.00 Wita.

Jumlah karyawan terjadi penurunan dari tahun 2011-2015, hal ini dikarenakan PT. Sariguna Prima Tirta Pulau Sari Kecamatan Bati-Bati Kabupaten Tanah Laut perlahan mulai menggantikan tenaga manusia dengan tenaga mesin, dengan target produksi meningkat setiap tahunnya, sedangkan hasilnya atau out put belum maksimal, ini dapat diketahui dari persentase terjadi penurunan, untuk mengejar target produksi manajemen PT. Sariguna Prima Tirta Pulau Sari Kecamatan Bati-Bati Kabupaten Tanah Laut melakukan berbagai cara salah satunya adalah memotivasi karyawan. Namun munculnya kendala-kendala menjadi penghambat motivasi kerja karyawan seperti adanya perusahaan sejenis dengan bidang usaha yang hampir sama, memberikan gaji karyawan yang lebih tinggi, sehingga menyebabkan karyawan diperusahaan menuntut hal yang sama. Kemudian dengan minimnya tunjangan yang diberikan kepada karyawan. Tunjangan yang diberikan oleh perusahaan yaitu tunjangan kesehatan dan tunjangan hari raya, kedua tunjangan ini diberikan kepada karyawan dengan persyaratan tertentu yaitu masa kerja di atas dua tahun.

Sumber daya manusianya dalam perusahaan adalah karyawan. Hasibuan (2010) menjelaskan bahwa karyawan merupakan penjual jasa (pikiran dan tenaganya). Dalam hal ini karyawan wajib dan terikat untuk mengerjakan pekerjaan yang diberikan pimpinan. Dari penjelasan tersebut dapat disimpulkan bahwa karyawan mempunyai kewajiban memberikan tenaga serta pikirannya untuk kepentingan perusahaan. Semua karyawan diperusahaan wajib mengembangkan potensinya sesuai dengan tujuan perusahaan. Karyawan merupakan aset utama bagi perusahaan karena tanpa adanya karyawan aktivitas perusahaan tidak akan terjadi. Karyawan berperan aktif dalam menetapkan rencana, sistem, proses, dan tujuan yang ingin dicapai perusahaan. Dengan adanya imbal balik yang baik antara pimpinan perusahaan dengan karyawan produktivitas kerja karyawan akan semakin meningkat, karyawan merasa dihargai yang secara tidak langsung karyawan akan bekerja sepenuh hati dengan memaksimalkan potensi yang dimilikinya, dengan jangka panjang tujuan perusahaan dapat dicapai.

Berdasarkan uraian singkat tersebut, peneliti tertarik untuk melakukan kajian lebih mendalam tentang pengaruh motivasi kerja karyawan terhadap produktivitas kerjanya. Dengan demikian ditetapkan rumusan masalah dalam penelitian ini adalah apakah motivasi kerja berpengaruh terhadap produktivitas kerja karyawan pada PT. Sariguna Prima Tirta Pulau Sari Kecamatan Bati-Bati Kabupaten Tanah Laut ? Kemudian tujuan diadakannya penelitian ini adalah untuk mengetahui dan membuktikan pengaruh motivasi kerja terhadap produktivitas kerja karyawan pada PT. Sariguna Prima Tirta Pulau Sari Kecamatan Bati-Bati Kabupaten Tanah Laut. Hasil penelitian ini diharapkan dapat dijadikan sebagai bahan masukan yang bermanfaat bagi PT. Sariguna Prima Tirta Pulau SariKecamatan Bati-Bati mengenai motivasi kerja dalam meningkatkan produktivitas kerja karyawannya. Mengacu pada rumusan masalah yang telah dikemukakan sebelumnya, maka hipotesis penelitian yang diajukan sebagai jawaban sementara dan masih harus dibuktikan kebenarannya adalah Motivasi kerja berpengaruh signifikan terhadap produktivitas kerja karyawan pada PT. Sariguna Prima Tirta Pulau Sari Kecamatan Bati-Bati Kabupaten Tanah Laut. 


\section{Kajian Literatur}

Panggabean (2002) menyatakan bahwa sumber daya manusia dalam suatu organisasi perusahaan sangat penting karena mempunyai peranan dalam keberlangsungan hidup organisasi perusahaan. Hal ini menunjukkan bahwa sumber daya manusia dalam suatu perusahaan memegang peranan penting dalam meningkatkan kemajuan dan kelangsungan hidup organisasi. Menurut Fahmi (2013) untuk mewujudkan suatu tujuan perusahaan agar bisa menerapkan konsep manajemen kinerja berkualitas dan profesional maka perlu kita pahami yang menjadi tujuan menyeluruh dan spesifik dari manajemen kinerja. Dalam hal ini adalah tujuan menyeluruh manajemen kinerja adalah untuk menumbuhkan suatu budaya di mana individu dan kelompok bertanggung jawab atas kelanjutan peningkatan proses bisnis dan peningkatan keterampilan dan kontribusi mereka sendiri. Artinya peningkatan manajemen kinerja bukan hanya berpengaruh pada peningkatan hasil perusahaan saja, namun lebih dari itu yaitu mampu menjadi nilai tambah bagi karyawan. Seorang karyawan pada saat diterapkannya konsep manajemen kinerja maka kemampuan dan kualitas dalam bekerja juga menjadi lebih baik, karena karyawan telah terbiasa bekerja sesuai dengan konsep tujuan dan elemen manajemen kinerja.

Kegiatan yang dilakukan oleh seseorang dalam bekerja didorong oleh suatu kekuatan dalam diri seseorang tersebut, kekuatan pendorong inilah yang disebut motivasi. Motivasi kerja karyawan dalam suatu organisasi dapat dianggap sederhana dan dapat pula menjadi masalah yang komplek, karena pada dasarnya manusia mudah untuk dimotivasi dengan memberikan apa yang menjadi keinginannya. Menurut Hasibuan dalam Sunyoto (2013) yang dimaksud motivasi adalah suatu kekuatan yang dihasilkan dari keinginan seseorang untuk memuaskan kebutuhan-kebutuhannya.

Motivasi menjadi penting karena dalam motivasi diharapkan setiap karyawan mau bekerja keras dan antusias untuk mencapai produktivitas kerja yang tinggi, perilaku seseorang dipengaruhi dan dirangsang oleh keinginan, pemenuhan kebutuhan serta tujuan dan kepuasannya.

Widodo (2015) untuk meningkatkan produktivitas suatu perusahaan bukanlah dengan cara bekerja lebih keras, tetapi bekerja lebih cerdas. Umumnya organisasi menuntut untuk dapat menghasilkan kerja yang lebih besar, tetapi dengan menggunakan sumber daya manusia, uang, waktu, tempat dan sumber lainnya secara lebih hemat. Sunyoto (2013) faktor produktivitas manusia memiliki peran besar dalam menentukan sukses suatu usaha. Secara konseptual produktivitas manusia sering disebuat sikap mental yang selalu memiliki pandangan bahwa mutu kehidupan hari ini lebih baik dari kemarin dan hari esok lebih baik dari hari ini. Maka produktivitas harus dapat ditingkatkan dengan berbagai faktor yang dapat dipenuhi. Faktor-faktor yang dapat mempengaruhi antara lain pendidikan dan pelatihan ketrampilam, gizi, nutrisi dan kesehatan, bakat atau bawaan motivasi, kesempatan kerja, kesempatan manajemen dan kebijakan sarana pemerintah.

Menurut Simamora (2010) faktor-faktor yang digunakan dalam pengukuran produktivitas kerja meliputi kuantitas kerja, kualitas kerja dan ketepatan waktu. Kuantitas kerja adalah merupakan suatu hasil yang dicapai oleh karyawan dalam jumlah tertentu dengan perbandingan standar ada atau ditetapkan oleh perusahaan. Kualitas kerja adalah merupakan suatu standar hasil yang berkaitan dengan mutu dari suatu produk yang dihasilkan oleh karyawan dalam hal ini merupakan suatu kemampuan karyawan dalam menyelesaikan pekerjaan secara teknis dengan perbandingan standar yang ditetapkan oleh perusahaan. Ketepatan waktu merupakan tingkat suatu aktivitas diselesaikan pada awal waktu yang ditentukan, dilihat dari sudut koordinasi dengan hasil output serta memaksimalkan waktu yang tersedia untuk aktivitas lain. Ketepatan waktu diukur dari persepsi karyawan terhadap suatu aktivitas yang disediakan diawal waktu sampai menjadi output. 
Sunyoto (2013) tantangan utama dari kepegawaian adalah bagaiamana meningkatkan produktivitas kerja pegawai sekaligus meningkatkan kepuasan kerja dan pengembangan atau pengelolaan sumber daya manusia dalam usaha peningkatan produktivitas pengelolaan sumber daya manusia tidak cukup hanya dengan melakukan program manajemen sumber daya manusia seperti melakukan program manajemen sumber daya manusia seperti analisis jabatan, perencanaan karier, penggajian, penilaian kerja, orientasi dan pelatihan meskipun diakui bahwa pelaksanaan program itu dengan baik merupakan faktor penting masih ada hal lain yang perlu dilakukan yaitu meningkatkan kualitas kehidupan kerja sebagai usaha untuk merespon kebutuhan pegawai.

Usaha ini dapat dilakukan melalui pendekatan struktural yaitu dilakukan dengan merancang ulang pekerjaan, dengan melibatkan pegawai dalam proses pengambilan keputusan melalui tim atau dengan melakukan perubahan pengorganisasian dan pendekatan proses dengan melalui pelaksanaan komunikasi yang efektif, peningkatan disiplin, penanggulangan stress, bimbingan dan konseling serta peningkatan keselamatan dan kesehatan kerja.

\section{Metode Penelitian}

Variabel bebas dalam penelitian ini adalah motivasi kerja. Variabel bebas ini diberi simbol X. sedangkan Variabel Terikat dalam penelitian ini adalah produktivitas kerja, dengan disimbolkan menggunakan simbol Y.

Motivasi kerja (X) dalam penelitian ini adalah energi yang menggerakkan diri seseorang untuk mencapai tujuan perusahaan serta memenuhi kebutuhan-kebutuhan yang dinginkan, dengan indikatornya (X1) Kebutuhan fisiologis, (X2) Kebutuhan sosial, dan (X3) Kebutuhan prestise. Selanjutnya variabel (Y) Produktivitas kerja adalah perbandingan antara jumlah barang yang dihasilkan dengan jumlah karyawan yang mengerjakannya, dengan indikator (Y1) Kuantitas kerja, (Y2) Kualitas kerja, dan (Y3) Ketepatan waktu kerja. Setiap pertanyaan diberikan skor dari yang nilainya sangat positif hingga dengan sangat negatif. Responden hanya memberikan tanda silang atau lingkaran pada alternatif jawaban yang telah disediakan dan selanjutnya seluruh jawaban responden akan dianalisis sesuai dengan tujuannya dengan menggunakan program SPSS for Windows.

Data dalam penelitian ada dua jenis yaitu data primer dan data sekunder. Data primer dalam penelitian ini diperoleh dari hasil penyebaran angket kepada 44 orang responden, selanjutnya data sekunder berasal dari perolehan observasi, wawancara terhadap karyawan

PT. Sariguna Prima Tirta Pulau Sari Bati-Bati serta dokumen yang ditemukan. Penetapan jumlah sampel dalam penelitian ini dilakukan dengan menggunakan rumus Slovin.

Hasil jawaban responden melalui angket kemudian dimasukan ke dalam tabulasi yang dipergunakan untuk mempermudah dan memperjelas permasalahan sebelum dilaksanakan perhitungan dengan menggunakan aplikasi SPSS. Teknik analisis data yang digunakan adalah analisis deskriptif kualitatif, oleh sebab itu peneliti membuat gipotesis sebagai asumsi awal untuk menjelaskan fenomena yang terjadi, selanjutnya diproses dengan menggunakan program SPSS for Windows.

\section{Hasil Penelitian dan Pembahasan}

Data variabel penelitian yang telah diuji validitas dan reliabilitasnya dan telah dinyatakan valid dan reliabel, kemudian diolah untuk perthitungan estimasi regresi. Perhitungan ini dilakukan dengan menggunakan bantuan program SPSS for Windows dengan hasil terlihat pada tabel 1. 
Tabel 1. Hasil Estimasi Regresi Linier Sederhana

\begin{tabular}{lcc}
\hline \multicolumn{1}{c}{ Variabel Bebas } & Variabel Terikat & Koefisien Regresi \\
\hline Motivasi Kerja & Produktivitas & 0,719 \\
\hline Constanta & 18,165 & \\
\hline Koefisien Determinasi & 0,633 & \\
\hline $\mathrm{T}_{\text {Hitung }}$ & 8,510 & \\
\hline $\mathrm{T}_{\text {Tabel }}$ (44-2) taraf 5\% & 2,02 &
\end{tabular}

Berdasarkan konstanta dan koefisien regresi pada tabel 1, maka dapat disusun persamaan regresi linier sederhana sebagai berikut: $\mathrm{Y}=18,165+0,719 \mathrm{X}$

Dalam analisis data perlu dilakukan uji asumsi klasik terlebih dahulu untuk menghindari munculnya bias dalam analisis data serta untuk menghindari kesalahan. Adapun pengujian terhadap asumsi-asumsi regresi linier atau disebut juga dengan pengujian klasik meliputi uji normalitas, uji heterokedastisitas.

Uji normalitas bertujuan untuk menguji apakah dalam sebuah model regresi, variabel dependen, variabel independen atau keduanya mempunyai distribusi normal atau tidak. Model regresi yang baik adalah distribusi data normal atau mendekati normal. Berikut P-Plot hasil pengujian.

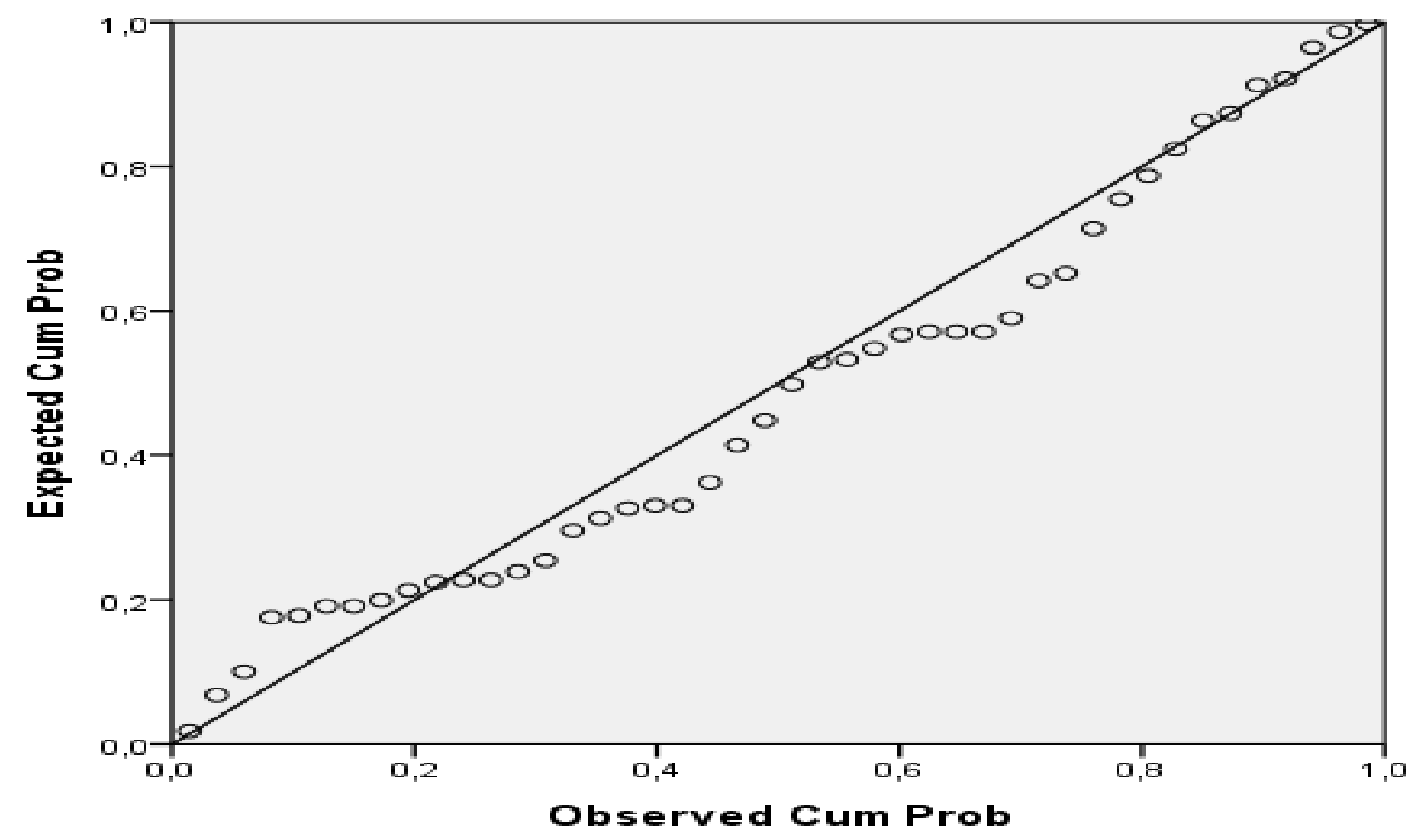

Gambar 1. Grafik P-Plot Uji Normalitas

Berdasarkan pada out put P-Plot di atas dapat diketahui bahwa data menyebar disekitar garis diagonal dan mengikuti garis diagonal yang berarti bahwa dalam penelitian ini telah lolos salah satu uji asumsi klasik yaitu uji normalitas.

Uji Heteroskedastisitas digunakan untuk menguji apakah dalam model regresi linier kesalahan pengganggu mempunyai varians yang sama atau tidak dari satu pengamatan ke pengamatan lainnya. Uji Heterokedastisitas biasa juga disebut uji homogenitas. Uji ini dapat 
juga dilihat dari plot datanya atau pada tabel scatterplot (grafiknya bisa dilihat pada Gambar 2).

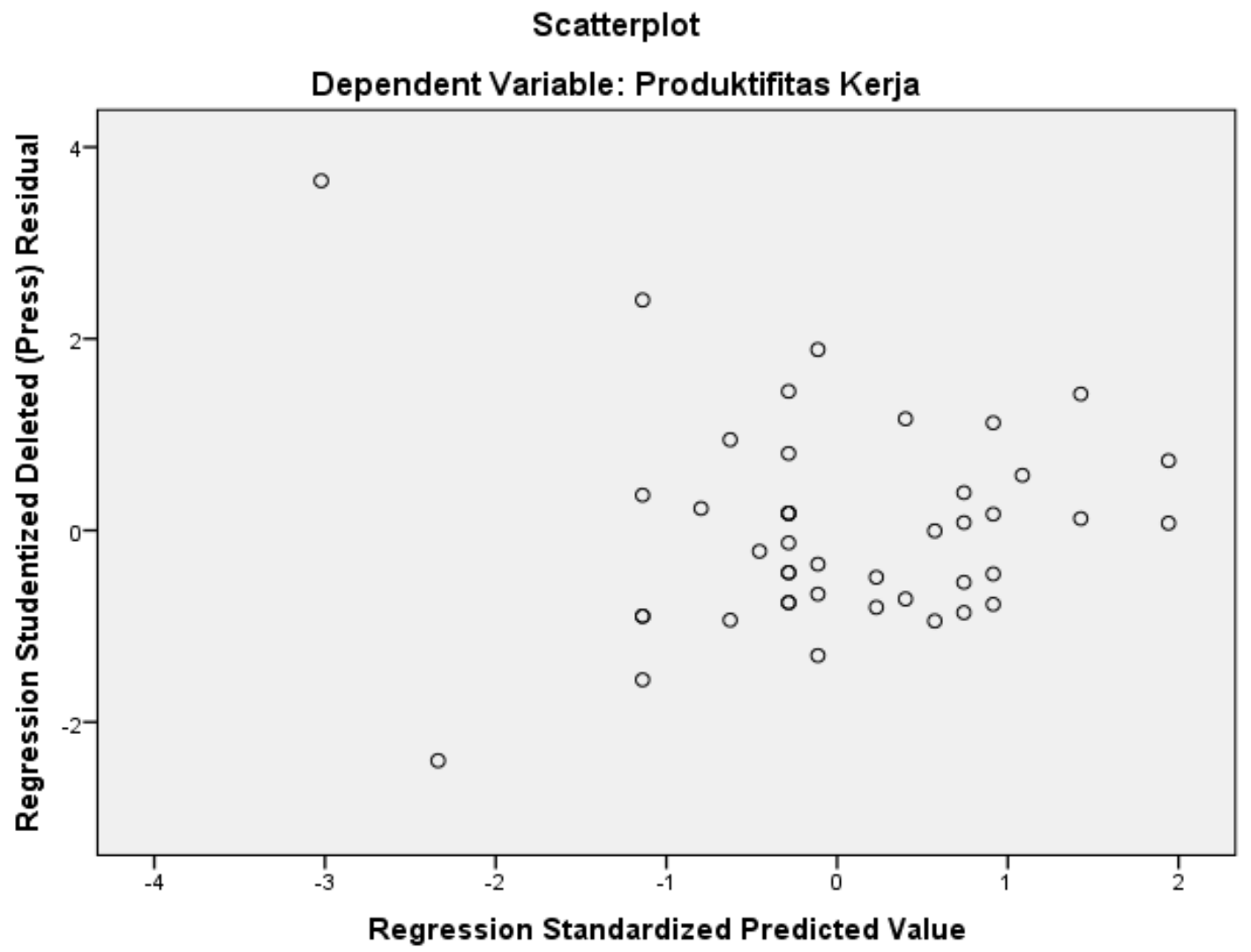

Gambar 2. Hasil Uji Heteroskedastisitas

Titik-titik variabel independen terhadap variabel dependen yang mengisi diagram scatterplot seperti tampak pada gambar 2 tidak ditemukan adanya masalah heterokedastisitas.

Pengaruh variabel motivasi kerja terhadap produktivitas kerja karyawan PT. Sariguna Prima Tirta Pulau Sari Kecamatan Bati-Bati Kabupaten Tanah Laut dapat diketahui dari uji t. Kriteria pengujian uji $\mathrm{t}$ dengan cara membandingkan $\mathrm{t}$ hitung dengan $\mathrm{t}$ tabel/kritis, hasil $\mathrm{t}$ hitung terlihat pada tabel Coefficientspada print out SPSS for Windows seperti ditunjukkan pada Tabel 2.

Tabel 2. Hasil t hitung

\begin{tabular}{|c|c|c|c|c|c|c|}
\hline \multicolumn{7}{|c|}{ Coefficients $^{a}$} \\
\hline \multirow{2}{*}{\multicolumn{2}{|c|}{ Model }} & \multicolumn{2}{|c|}{ Unstandardized Coefficients } & \multirow{2}{*}{$\begin{array}{c}\text { Standardized Coefficients } \\
\text { Beta }\end{array}$} & \multirow[t]{2}{*}{$\mathrm{t}$} & \multirow[t]{2}{*}{ Sig. } \\
\hline & & $\mathrm{B}$ & Std. Error & & & \\
\hline \multirow[t]{2}{*}{1} & (Constant) & 18,165 & 4,895 & & 3,711 &, 001 \\
\hline & Motivasi Kerja & ,719 & ,084 & ,796 & 8,510 &, 000 \\
\hline
\end{tabular}

a. Dependent Variable: produktivitas Kerja 
Berdasarkan data estimasi regresi angka thitung adalah 8,510 sedangkan nilai t tabel dengan tingkat signifikasi 5\% (44-2) adalah 2,02 (tabel distribusi t). Jika angka tersebut dibandingkan nampak jika t hitung lebih besar dari t tabel yaitu 8,510 > 2,02. Ini berarti variabel motivasi kerja berpengaruh signifikan terhadap produktivitas kerja karyawan PT. Sariguna Prima Tirta Pulau Sari Kecamatan Bati-Bati Kabupaten Tanah Laut pada taraf uji 5\%, dengan demikian Hipotesis Nol (Ho) secara keseluruhan ditolak, sebaliknya hipotesis alternatif (Ha) secara keseluruhan diterima.

Berdasarkan pada hasil perhitungan diketahui 0,633 artinya kemampuan variabel motivasi kerja mempengaruhi variabel produktivitaskerja sebesar $63,3 \%$, sedangkan sisanya sebesar 36,7 \% dijelaskan oleh variabel-variabel lain yang tidak diteliti dalam penelitian ini, sehingga bisa menjadi celah bagi peneliti selanjutnya untuk meningkatkan nilai persentase dari koefisien determinasi tersebut.

Berdasarkan pada hipotesis yang diajukan Ha yang berbunyi "Motivasi kerja berpengaruh signifikan terhadap produktivitas kerja karyawan pada PT. Sariguna Prima Tirta Pulau Sari Kecamatan Bati-Bati Kabupaten Tanah Laut" diterima, hal ini dibuktikan dengan nilai $\mathrm{t}$ hitung lebih besar dari $\mathrm{t}$ tabel yaitu $8,510>2,02$. Hal ini berarti motivasi kerja berpengaruh secara signifikan terhadap produktivitas kerja pada PT. Sariguna Prima Tirta Pulau Sari Kecamatan Bati-Bati Kabupaten Tanah Laut.

Hasil persamaan regresi berdasarkan perhitungan dengan menggunakan program SPSS For Windows yaitu: $\mathrm{Y}=18,165+0,719 \mathrm{X}$. Nilai konstanta sebesar 18,165 mempunyai makna bahwa jika tidak ada variabel motivasi kerja, maka variabel produktivitas kerja sebesar 18,165. Nilai koefisien regresi sebesar 0,719 mempunyai makna bahwa, bila terjadi perubahan yang meningkat sebesar 1 (satu) pada variabel motivasi kerja dengan menganggap faktor lain tetap maka akan mengakibatkan terjadinya perubahan peningkatan sebesar 0,719 terhadap produktivitas kerja.

Berdasarkan hasil perhitungan dengan menggunakan program SPSS For Windows diketahui bahwa koefisien determinasi sebesar 0,633 yang berarti bahwa motivasi kerja mempengaruhi produktivitas kerja sebesar 63,3\% sedangkan sisanya 36,7 \% dijelaskan oleh variabel lain selain motivasi kerja.

\section{Kesimpulan}

Berdasarkan hasil penelitian, maka dapat disimpulkan bahwa hasil Persamaan Regresi Sederhana dalam penelitian ini adalah $\mathrm{Y}=18,165+0,719 \mathrm{X}$. Berdasarkan hasil uji t diketahui variabel motivasi kerja berpengaruh positif dan signifikan terhadap poduktivitas kerja, karena pada taraf signifikasi $5 \%$ t hitung lebih besar dari t tabel $(8,510>2,02)$. Koefisien determinasi $\left(\mathrm{r}^{2}\right)$ sebesar 0,633 yang berarti kemampuan variabel motivasi kerja (X) dapat menjelaskan variabel produktivitas kerja (Y) sebesar 63,3\% sedangkan sisanya 36,7\% dipengaruhi oleh variabel lain yang tidak diteliti dalam penelitian ini.

Kesimpulannya, motivasi memang memiliki pengaruh yang positif terhadap produktivitas kerja, yang artinya jika kita ingin meningkatkan produktivitas kerja di PT. Sariguna Prima Tirta Pulau Sari Kecamatan Bati-Bati Kabupaten Tanah Laut, maka perusahaan harus lebih memperhatikan motivasi yang diberikan kepada mereka.

\section{DAFTAR PUSTAKA}

Fahmi, Irham. 2013. Perilaku Organisasi Teori, Aplikasi dan Kasus. Bandung: Alfabeta. Hasibuan, Malayu. 2010. Manajemen Sumber Daya Manusia. Jakarta : PT.Bumi Aksara. Panggabean, Mutiara. 2002. Manajemen Sumber Daya Manusia. Jakarta. Ghalia Indonesia. Simamora, Henry. 2010. Manajemen Sumber Daya Manusia. Yogyakarta: STIE YKPN. Sugiyono. 2012. Metode Penelitian Kuantitatif Kualitatif . Bandung: Alfabeta. 
Sulaiman, Wahid. 2010. Jalan Pintas Menguasai SPSS 17. Yogyakarta. Andi. Sunyoto Danang, 2013. Penelitian Sumber Daya Manusia. Yogyakarta. CAPS.

Widodo Suparno Eko, 2015. Manajemen Pengembangan Sumber Daya Manusia. Yogyakarta. Pustaka Pelajar. 